\title{
Fiber Laser Welding of 1700-MPa, Ultrahigh-Strength Steel
}

\author{
This study investigates the appearance, microstructure, \\ and mechanical properties of laser welded joints
}

\author{
BY C. LUO, Y. CAO, Y. ZHAO, L. ZHAO, AND J. SHAN
}

\begin{abstract}
This paper investigated the appearance, microstructure, and mechanical properties of laser welded joints for 1700 $\mathrm{MPa}$, ultrahigh-strength steel (UHSS) with $6 \mathrm{~mm}$ thickness. The results indicate welding speed was the dominant factor that affected appearance quality. A sound weld without underfill can be obtained when the speed was limited to approximately $2-3 \mathrm{~m} / \mathrm{min}$. Two softening mechanisms exist in the heat-affected zone (HAZ). In the intercritical heataffected zone (ICHAZ), ferrite appears and the hardness drops sharply. For the subcritical heat-affected zone (SCHAZ), the microstructure was tempered martensite with precipitation of carbides and the high temperature temper results in the minimum hardness. With a martensitic structure in the weld metal and a narrow softening zone in the HAZ, more than a $94 \%$ joint efficiency was achieved in tensile testing. Only about a 40-deg maximum bending angle was obtained during a bend test, as plastic deformation mainly concentrates in the softening zone due to nonuniform hardness distribution. The study also found that the existence of porosities in the joints had significant affects on the ductility, toughness, and fracture mechanism, but little affect on the joint strength. For the joints without porosities, the fractures from tensile and bend tests both initiated at the zone with the minimum hardness and propagated along the 45-deg direction. But when porosities existed in the joints, fractures occurred completely in the weld metal, which resulted in a smaller elongation and bending angle as well as impact energy. However, the tensile strength was similar to an average value.
\end{abstract}

\section{KEYWORDS}

- Laser Welding • 1700-MPa, Ultrahigh-Strength Steel

- Ferrite • Tempered Martensite • Softening • Fracture

\section{Introduction}

Weight reduction with increased strength and performance is desired to meet the global demand for safe, environmentally friendly, and energy-efficient vehicles. The demand can be satisfied with the use of ultrahigh-strength steel (UHSS), which has superior performance without an extra weight increase (Refs. 1-4). Compared to conventional carbon-hardened steel, UHSS is stronger, harder, and possesses a high strength-to-weight ratio as well as good toughness (Ref. 4). The combination of tensile strength up to $1700 \mathrm{MPa}$ and high hardness of more than $500 \mathrm{HV}$ can provide excellent resistance to penetration and shock (Ref. 5). Therefore, UHSS is widely used in critical protection systems such as cash transport vehicles, diplomatic vehicles, and hull construction (Refs. 5, 6).

As the most essential joining technique used in the automotive industry, the welding process needs to be high efficiency and high quality. Ultrahigh-strength steel is difficult to weld due to its high hardenability, which makes it prone to cold cracking, especially for steel with a strength of more than $1380 \mathrm{MPa}$ (Refs. 7, 8). Currently, the most common welding process for UHSS is arc welding with filler metal (Refs. 5, 9, 10). Austenitic and ferritic consumables are often used since ferrite can improve the stress state (Ref. 11) and austenite can increase the solubility of hydrogen (Ref. 12), both of which will decrease the cold cracking tendency of joints. However, the use of undermatching consumables makes the weld metal become the weak zone of the joints (Refs. 13, 14). On the basis of related review (Refs. 15-17), it can be found that the joint efficiency (tensile strength ratio of joints to base metal) is generally lower than $60 \%$ for UHSS with a tensile strength of more than $1500 \mathrm{MPa}$. Most of the joints fail in the weld metal since the microstructure is mainly composed of austenite and $\delta$-ferrite (Refs. 17,18 ). Some research has been done to improve joint strength by adjusting the microstructure of the weld metal (Refs. 17-19). Joint efficiency could reach $76 \%$ by keeping the weld at $623 \mathrm{~K}\left(350^{\circ} \mathrm{C}\right)$ for $6 \mathrm{~h}$ to obtain a carbide-free bainitic microstructure in the weld metal (Ref. 17). The joints fractured in the heat-affected zone (HAZ) since highheat input led to severe softening. However, the joint strength was still unsatisfactory.

One effective technique to improve joint efficiency is lowering heat input (Ref. 16). Laser welding has characteristics of high power density and low heat input. The power density can be up to $10^{8} \mathrm{~W} / \mathrm{cm}^{2}$ (Ref. 20), which is about 1000 times higher than in conventional arc welding. The influence of laser heat input on the HAZ is significantly lower 


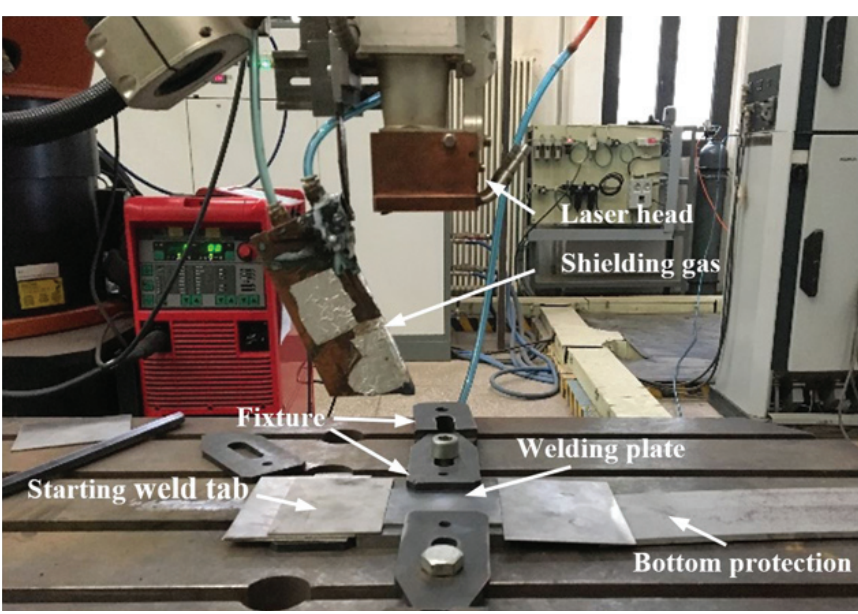

Fig. 1 - Experimental setup.

and the microstructure degradation is less (Ref. 20). Some researchers have found that laser welding forms a narrow weld, a restricted HAZ, and minimized softening in comparison with arc welding of UHSS (Ref. 21). More importantly, obtaining a martensitic structure in the weld metal strengthens UHSS joints (Ref. 4). But the high cooling rate of laser welding is at a great risk to cold cracking since martensite is sensitive to hydrogen cracks. However, lowhydrogen welding practices can help to reduce the amount of hydrogen in the joints (Ref. 22). Compared to arc welding, laser welding usually works in a clean environment and melts the base metal instead of the filler metal to fill the weld, which reduces hydrogen content at the source. Meanwhile, laser welded joints generally have better residual stress distributions with lower tensile residual stress (Refs. $23,24)$ and narrower regions sustaining the tensile residual stress (Refs. 24, 25). All of the above could be beneficial for reducing cold crack sensitivity of laser welded joints to some extent. Among commercial laser systems, fiber laser welding is the newest with several advantages over other laser types. Recent studies showed the HAZ and weld metal obtained by fiber laser welding are narrower than those formed by welding with other lasers (Ref. 26) and the tensile residual stresses of joints are the lowest (Ref. 27). Hence, fiber laser is appropriate for the welding of UHSS.

Currently, a number of research studies about laser welding of UHSS have been conducted (Refs. 2, 10, 26), but most of them mainly concentrate on steel plates with strengths below $1500 \mathrm{MPa}$. Limited works have been published regarding laser welding of UHSS with more than $1500 \mathrm{MPa}$, and only thin plates less than $3 \mathrm{~mm}$ in thickness are dis- cussed (Refs. 3, 4, 28). Mid-thick steel plates generally means plates with a thickness between 3 and $20 \mathrm{~mm}$. For laser welding of mid-thick UHSS, there might be some new problems such as forming defects and property inhomogeneity along the thickness direction. In consideration of the increasing application of stronger and thicker steels, it is essential to explore the actual laser welding properties of UHSS more than $1500 \mathrm{MPa}$ with midthickness.

The aim of this paper is to investigate laser welding characteristics of $1700 \mathrm{MPa}$ UHSS with $6 \mathrm{~mm}$ thickness. A $10-\mathrm{kW}$ fiber laser welding system was chosen to conduct the experiments. The effects of parameters on the formation of welds were studied. Also, the appearance, microstructures, and mechanical properties, including microhardness, tensile strength, and bending property as well as impact performance of the bead-on-plate joints, were assessed.

\section{Experimental Procedures}

In this study, $1700 \mathrm{MPa}$ UHSS plates were used. The chemical composition and mechanical properties of the base metal are shown in Tables 1 and 2, respectively. The plates have dimensions of approximately $200 \times 150 \times 6 \mathrm{~mm}^{3}$. The experimental setup is shown in Fig. 1. A 10-kW fiber laser with a beam parameter product of $7.5 \mathrm{~mm} \cdot \mathrm{mrad}$ was used. A collimation lens of $150 \mathrm{~mm}$, with a focal lens of $300 \mathrm{~mm}$ and a fiber diameter of $200 \mathrm{~mm}$, were employed to produce a focusing spot diameter of approximately $0.40 \mathrm{~mm}$. Table 3 shows experimental procedures. Full factorial experiments were performed to study joint quality. The laser power was from 6 to $10 \mathrm{~kW}$ with 1-kW increments, and the welding speed was from 1 to $6 \mathrm{~m} / \mathrm{min}$ with $1 \mathrm{~m} / \mathrm{min}$ increments. The defocusing distance was $0 \mathrm{~mm}$.

Before welding, samples were cleaned with emery paper and acetone to remove surface oxide and then held firmly in a bead-on-plate configuration (Fig. 1). High-purity argon (99.99\%) was used to shield both the top and bottom surface of samples at a flow rate of 25 and $5 \mathrm{~L} / \mathrm{min}$, respectively.

After welding, the cross sections of joints were sliced, polished, and finally etched with modified Fry's regent (50 $\mathrm{ml} \mathrm{HCl}+25 \mathrm{ml} \mathrm{HNO}_{3}+1 \mathrm{~g} \mathrm{CuCl}_{2}+150 \mathrm{ml} \mathrm{H}_{2} \mathrm{O}$ ) for about 3 s. Microstructures of the welded joints were observed using an optical microscope (OM) and a scanning electron microscope (SEM). The Vickers microhardness test was performed on the etched cross sections with a load of $500 \mathrm{~g}$ for a 15-s dwell time. The tensile property perpendicular to the welding direction was evaluated at room temperature. A threepoint bend test was carried out at room temperature with 6 times elbow diameter. Additionally, the Charpy impact test

Table 1 - Main Chemical Composition of Base Metal

\begin{tabular}{lcccccccc} 
Composition & $\mathrm{C}$ & $\mathrm{Mn}$ & $\mathrm{Cr}$ & $\mathrm{Mo}$ & $\mathrm{Ni}$ & $\mathrm{Si}$ & $\mathrm{Nb}$ & $\mathrm{Fe}$ \\
\hline Percent (wt-\%) & 0.3 & 0.3 & 0.8 & 0.3 & 0.8 & 0.3 & 0.05 & other \\
\hline
\end{tabular}

Table 2 - Mechanical Properties of Base Metal 


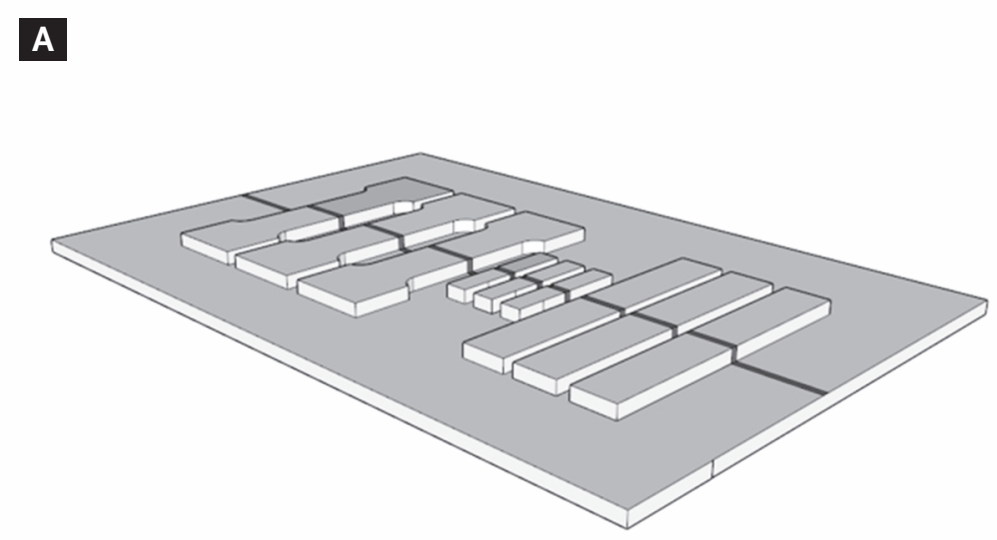

B
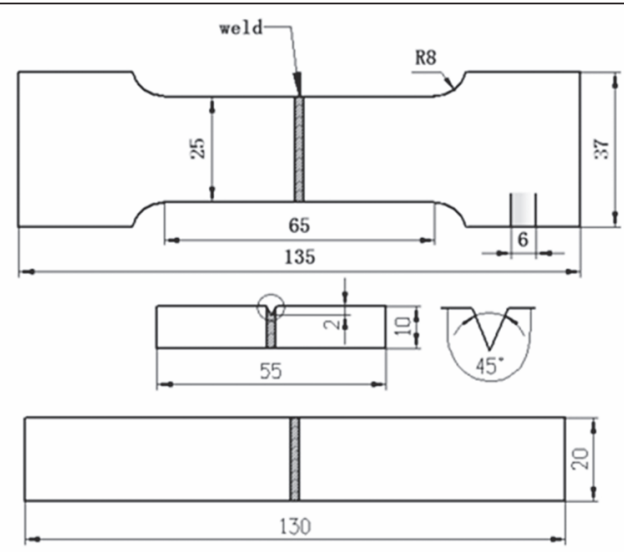

Fig. 2 - Sample distribution and size for mechanical properties testing. A - Schematic; B - detailed dimensions.

was evaluated at $-40^{\circ} \mathrm{C}$ with $\mathrm{V}$-notches located in the middle of the weld metal. The distribution and size of the test samples are shown in Fig 2. For each mechanical property test, three samples were tested to ensure statistical accuracy. Following the tensile, the fracture surface of the tested specimens was examined by SEM. Weld reinforcement on the face and root regions was removed by manual grinding before mechanical property tests were carried out.

\section{Experimental Results}

\section{Joint Quality}

Laser welding of thick section materials without filler metal is often accompanied by defects such as spatter, root humping, and pool sagging as well as root concavity, which would all result in undercut or even underfill (Refs. 29, 30). Previously, many studies have investigated the defects in laser welding (Refs. 31-34), but only isolated defects were generally focused on, and the distribution of defects under different parameters weren't discussed. This section shows the distribution of defects within the process window.

The defect distribution under different parameters is

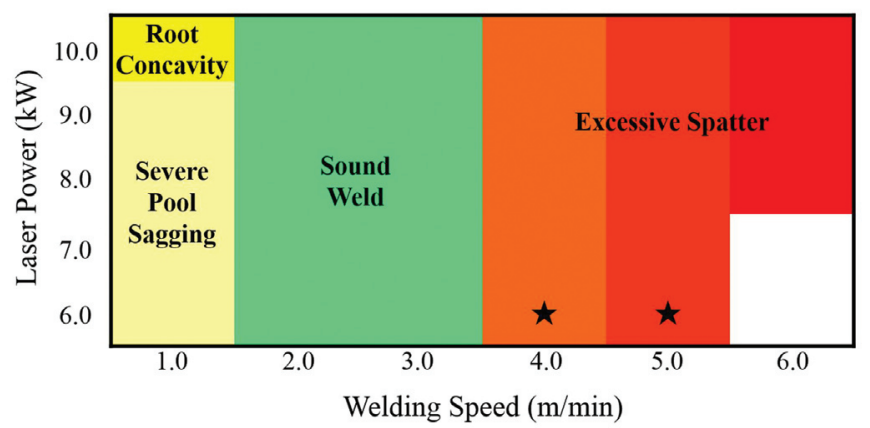

Fig. 3 - Forming defects distribution under different parameters. The five-pointed stars signify the occurrence of root humping.

shown in Fig. 3 and the five-pointed stars in it mean that root humping occurred. The welding appearance under different parameters are shown in Fig. 4. It can be seen that complete joint penetration welds were obtained, but the typical forming defects mentioned above emerged under different parameters. As illustrated in Fig. 3, large quantities of spatter are generated when the welding speed is more than
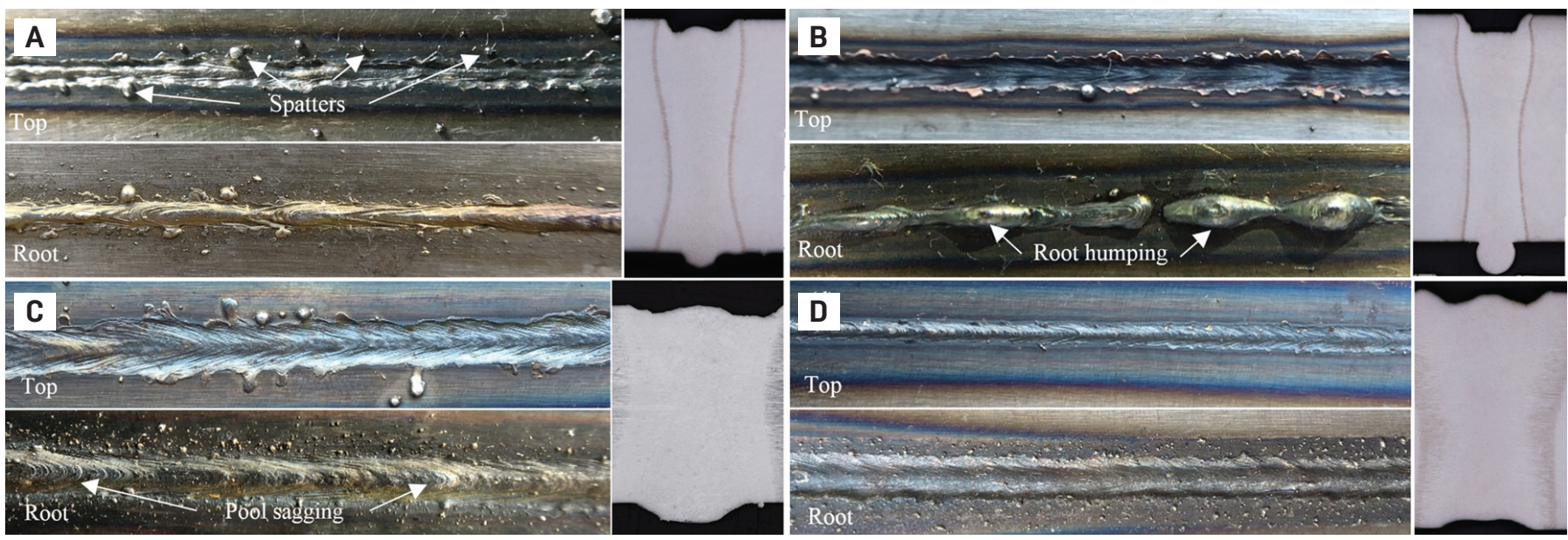

Fig. 4 - Welding appearance under different parameters. A - Spatters under $8 \mathrm{~kW}$ and $4 \mathrm{~m} / \mathrm{min}$; B - root humping under $6 \mathrm{~kW}$ and $4 \mathrm{~m} / \mathrm{min}$; C - pool sagging under $6 \mathrm{~kW}$ and $1 \mathrm{~m} / \mathrm{min}$; $D$ - root concavity under $10 \mathrm{~kW}$ and $1 \mathrm{~m} / \mathrm{min}$. 


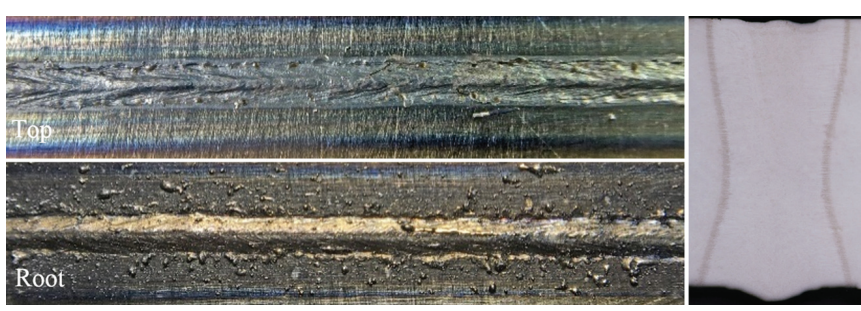

Fig. 5 - Appearance and cross section of a joint obtained under $10 \mathrm{~kW}$ and $2 \mathrm{~m} / \mathrm{min}$.

$4 \mathrm{~m} / \mathrm{min}$. The welding appearance can be seen in Fig. $4 \mathrm{~A}$. A lot of spatter is around the weld and obvious underfill can be seen on the cross section. Furthermore, root humping is observed under the condition of $6 \mathrm{~kW}$ and more than $4 \mathrm{~m} / \mathrm{min}$. As shown in Fig. 4B, root humping arose periodically, and deep underfill appeared on the corresponding top surface. Moreover, a severe pool sagging defect occurred at 1 $\mathrm{m} / \mathrm{min}$ with a power of 6 to $8 \mathrm{~kW}$. In Fig. $4 \mathrm{C}$, the whole root of the weld sags significantly. With a further increase in laser power, a significant root concavity appeared and the weld joint showed underfill on both the face and root regions, which means a lot of molten metal is out of the weld.

Consequently, to obtain a sound weld without obvious forming defects, the welding speed should be limited to 2-3 $\mathrm{m} / \mathrm{min}$ with a power of 6 to $10 \mathrm{~kW}$. The weld appearance under $10 \mathrm{~kW}$ and $2 \mathrm{~m} / \mathrm{min}$ is shown in Fig. 5 . It can be seen that the full shape without underfill was obtained. Three sets of parameters were selected to study mechanical properties of the laser weld joints in accordance with the process window of the sound weld and shown in Table 4.

Argon pores were found in weld metal under parameter 1 $(0.16 \mathrm{~kJ} / \mathrm{mm})$. As seen in Fig. 6 , there are some pores on the fracture surface of the weld metal under $0.16 \mathrm{~kJ} / \mathrm{mm}$ heat input, and the pores have a smooth inner wall with a spiral scouring trace. Columnar crystals are clearly observed. It can be identified as keyhole-type pores, namely argon pores. The existence of porosity may have some effect on the mechanical properties of joints. For parameters 2 and 3, several cross sections of samples were observed and no porosity was found.
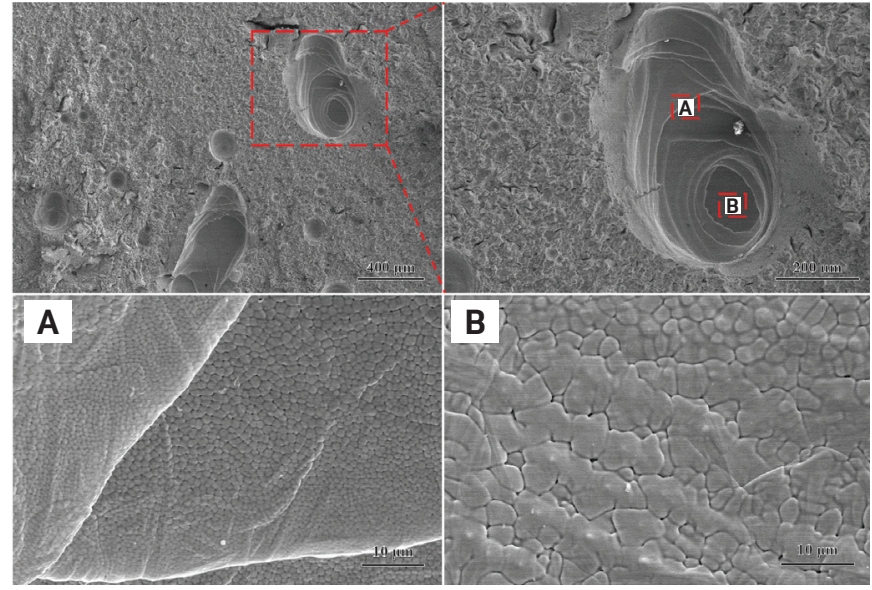

Fig. 6 - Magnified SEM photograph of porosity on the fracture surface of the weld metal under $0.16 \mathrm{~kJ} / \mathrm{mm}$.

\section{Microstructure}

Due to low-carbon content, the base metal microstructure is mainly composed of lath martensite (Ref. 4). The cooling rate is one of the most important factors influencing microstructure. Laser welding has low linear energy and high cooling rates $\left(2000^{\circ}-3000^{\circ} \mathrm{C} / \mathrm{s}\right)($ Ref. 10$)$, which promotes the diffusionless transformation of the prior austenite into martensite. The microstructures of the laser welded joint were observed by OM and SEM and are shown in Fig. 7.

Metallographic examination indicated that the joint is comprised of a weld metal (WM) and HAZ. As illustrated in Fig. 7A, the HAZ can be divided into four subregions: coarse-grained HAZ (CGHAZ), fine-grained HAZ (FGHAZ), intercritical HAZ (ICHAZ), and subcritical HAZ (SCHAZ).

As shown in Fig. 7A and B, the WM mainly contains lath martensite. Since the heat flow in the weld metal is highly directional toward the fusion boundary, the prior austenite grew to the columnar grains in a certain direction (Ref. 4). The prior columnar boundary developed during solidification is clearly observed in Fig. 7B. Additionally, Fig. 8 reveals

Table 3 - Experimental Procedure

Step Procedure

$1 \quad$ Performing full-factorial experiments to study joint quality

$2 \quad$ Selecting parameters with a sound weld and welding the UHSS plates within the parameters

3 Carrying out mechanical performance tests with the plates of step 2

Table 4 - Experiment Parameters Chosen for Mechanical Property Test

No. Laser Power (kW)

Welding Speed (m/min)

Heat Input $(\mathrm{kJ} / \mathrm{mm})$

\begin{tabular}{llll}
\hline 1 & 8 & 3 & 0.16 \\
2 & 6 & 2 & 0.18 \\
3 & 10 & 2 & 0.30 \\
\hline
\end{tabular}



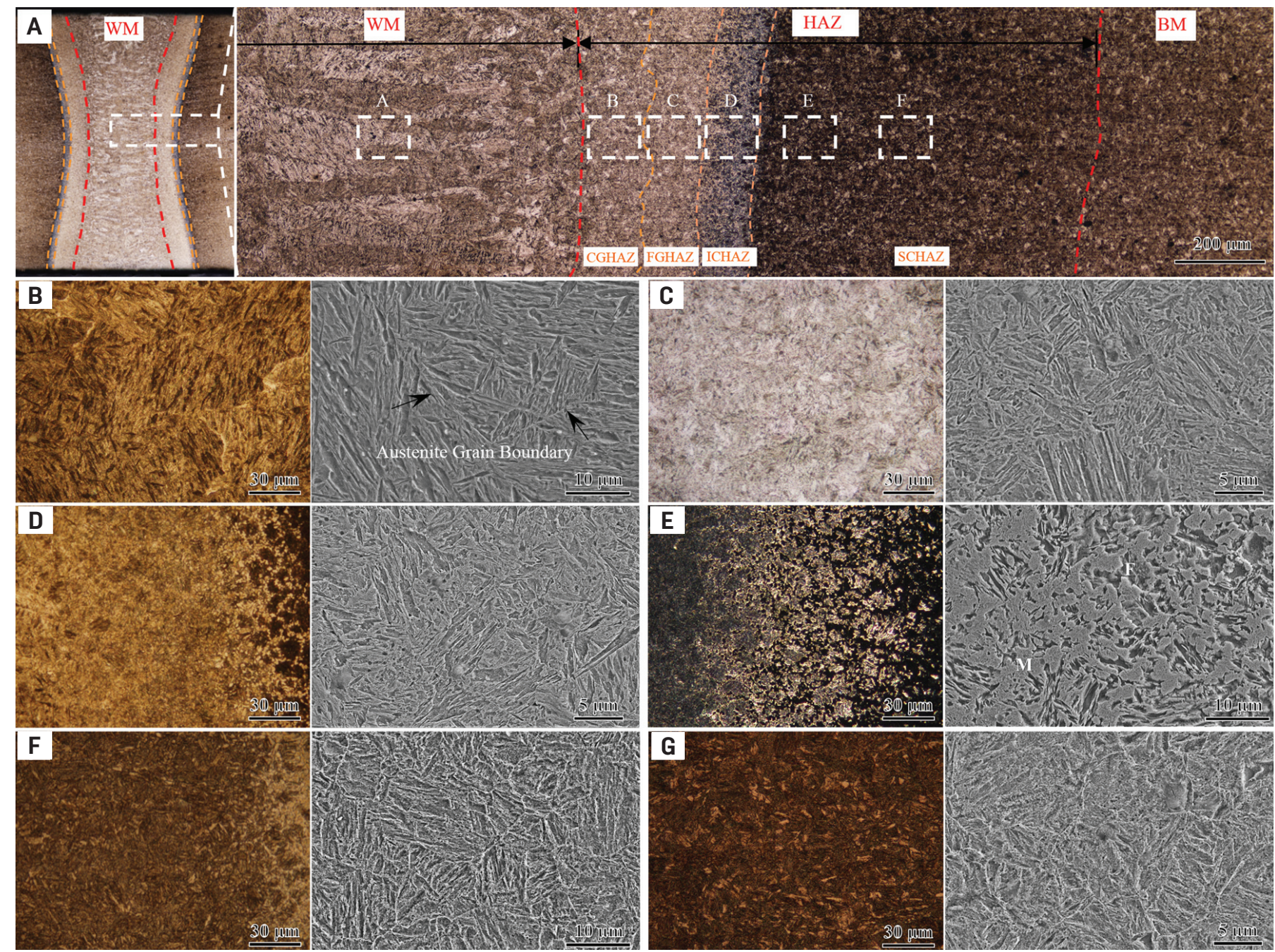

Fig. 7 - These OM and SEM micrographs show the microstructures in different subzones of the welded joints with $0.18 \mathrm{~kJ} / \mathrm{mm}$ heat input. A - Joint microstructures; B - WM; C - CGHAZ; D - FGHAZ; E - ICHAZ; F - SCHAZ near ICHAZ; G - SCHAZ.

that the prior austenite grew to the columnar grains in a certain direction and finally converged at the weld center. The weld center is almost planar. There is no equiaxed crystal around the weld center. The WM is mainly composed of columnar grains with obvious direction. The micrographs at the same magnification of the base metal and weld metal are shown in Fig. 9. Compared with the base metal, the size of lath martensite in the weld metal is slightly smaller due to the high cooling rate of laser welding.

In the CGHAZ and FGHAZ, the peak temperature during welding was more than $\mathrm{A}_{c 3}$ and full austenitizing occurred. As Fig. $7 C$ and $D$ indicate, the major microstructures of the FGHAZ and CGHAZ are still martensite. That is because the initial martensite is formed into austenite and then the subsequent cooling causes the austenite to transform into martensite again (Ref. 4). Since the CGHAZ is adjacent to the weld interface and the austenitizing is severe, the microstructure is lath martensite with a large prior-austenite grain size. The microstructure within the FGHAZ is lath martensite with a small prior-austenite grain size. The results agreed with findings of correlational research (Ref. 35).

The ICHAZ is obtained when the zone is heated to

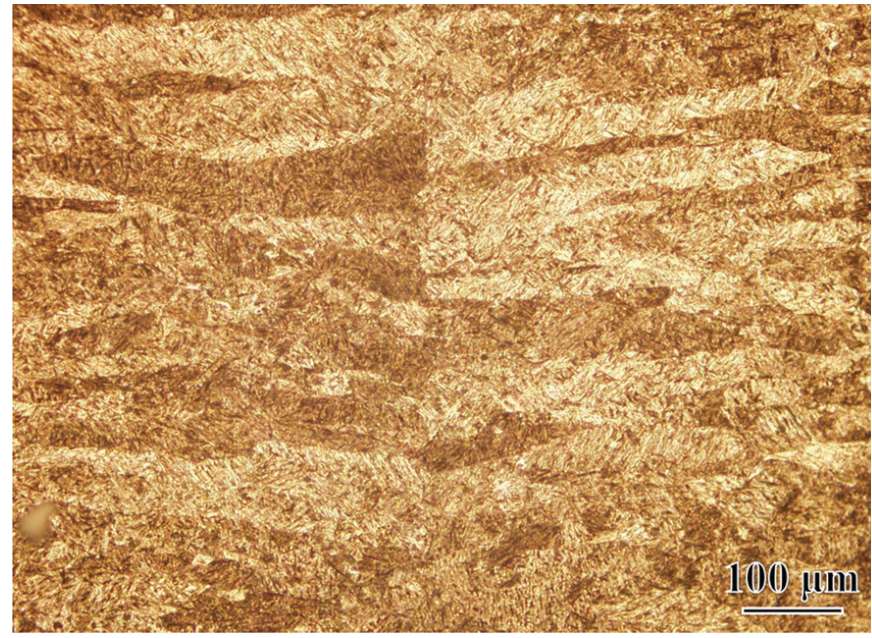

Fig. 8-OM micrographs showing the microstructures around the weld center.

$A_{c 1} \sim A_{c 3}$ (Ref. 36), and the SEM micrographs of the region are given in Fig. 10. According to the phase diagram, the marten- 

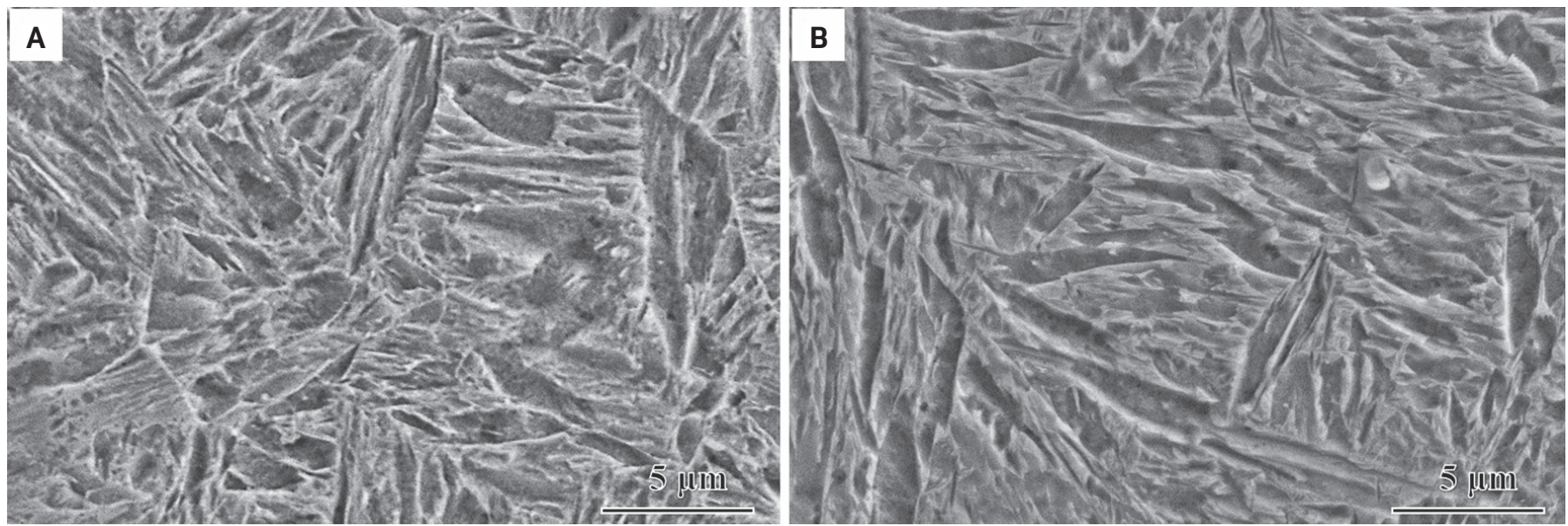

Fig. 9-Microstructure of the base metal and weld metal. A - Base metal; B - weld metal.

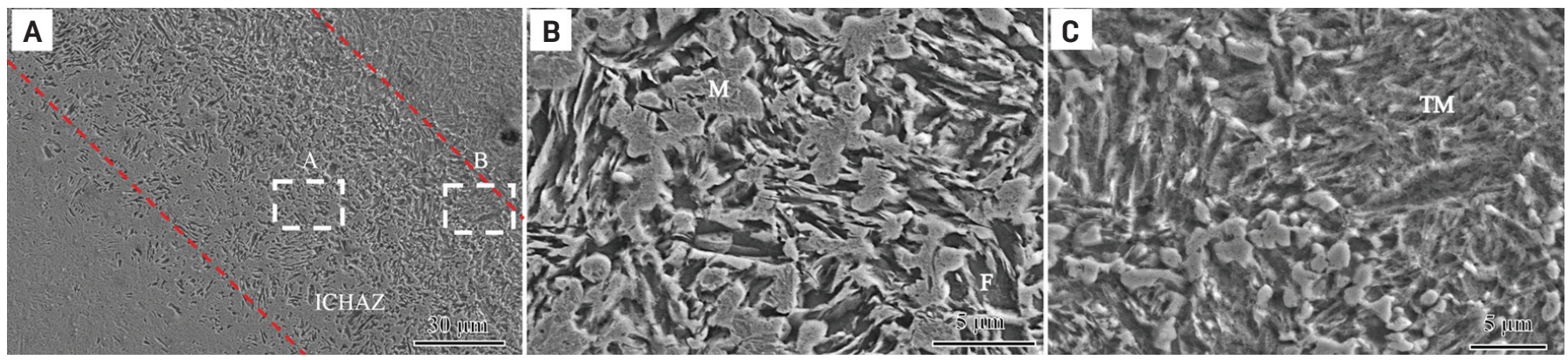

Fig. 10 - SEM micrographs showing the microstructures in different positions of the ICHAZ. A $-I C H A Z ; B-A$ region; $C-B$ region.

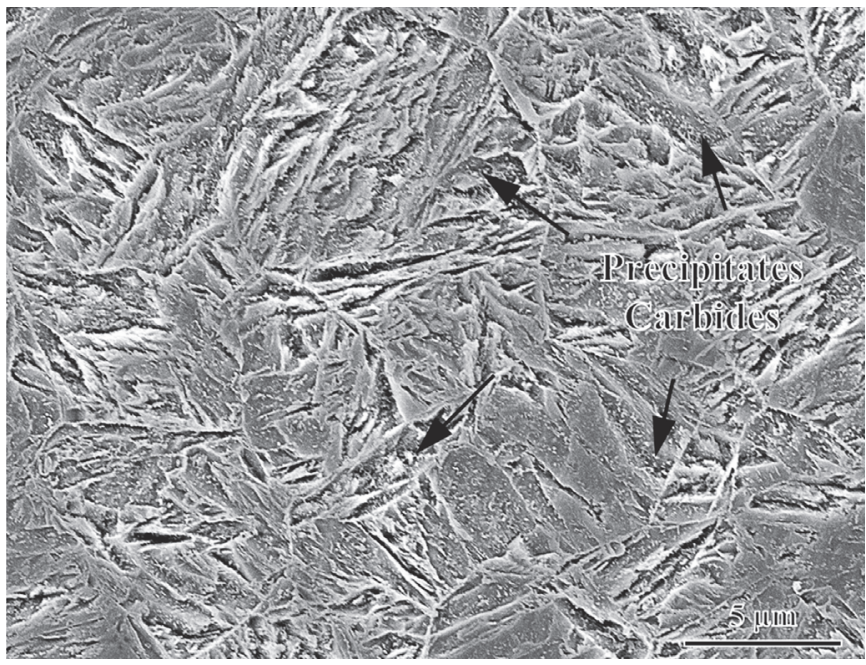

Fig. 11 - High-magnification SEM of the tempered martensite structure in the SCHAZ.

site of the base metal transforms into ferrite and austenite during the heating process, and carbon is mainly contained in austenite. After cooling, the austenite in the ICHAZ transforms into martensite (Ref. 37). As illustrated in Figs.7E and 10, the microstructure of the ICHAZ may be comprised of ferrite and martensite. Similar microstructural features are reported in previous works on resistance spot welding of advanced high-strength steels (AHSS) (Refs. 36, 37).
For the SCHAZ, the peak temperature is below $A_{c 1}$ and high-temperature tempering happens. It can be seen in Fig.7F and $\mathrm{G}$ that the microstructure in the SCHAZ could be tempered martensite. The high-magnification SEM micrographs of the SCHAZ are shown in Fig. 11. Ultrafine precipitates carbides can be found on the matrix of tempered martensite. Namely, the preexisting martensite decomposes and precipitates carbides (Ref. 38).

\section{Microhardness}

The hardness distributions of joints under different heat inputs are given in Fig. 12. The microindentations of different subregions of a joint with $0.18 \mathrm{~kJ} / \mathrm{mm}$ heat input are shown in Fig. 13. As indicated in Fig. 12, the hardness varies significantly.

The hardness of the WM is approximately 510-530 HV (Fig. 13A), and slightly higher than that of the base metal (about $500 \mathrm{HV}$ ) due to a smaller size of lath martensite in the weld metal. For the HAZ, the hardness increased gradually in the CGHAZ and reached a maximum in the FGHAZ, where the microstructure is lath martensite with a fine grain size. As shown in Fig. 13B, the maximum hardness is 578 HV. A sharp decrease occurred in the ICHAZ, which agreed with a previous report (Ref. 9). The hardness decreased from 574 to $406 \mathrm{HV}$, which may be in connection with the appearance of ferrite. As illustrated in Fig. 13D, the minimum hardness is obtained in the SCHAZ instead of the ICHAZ, and the minimum value is about $345 \mathrm{HV}$. The hardness in- 

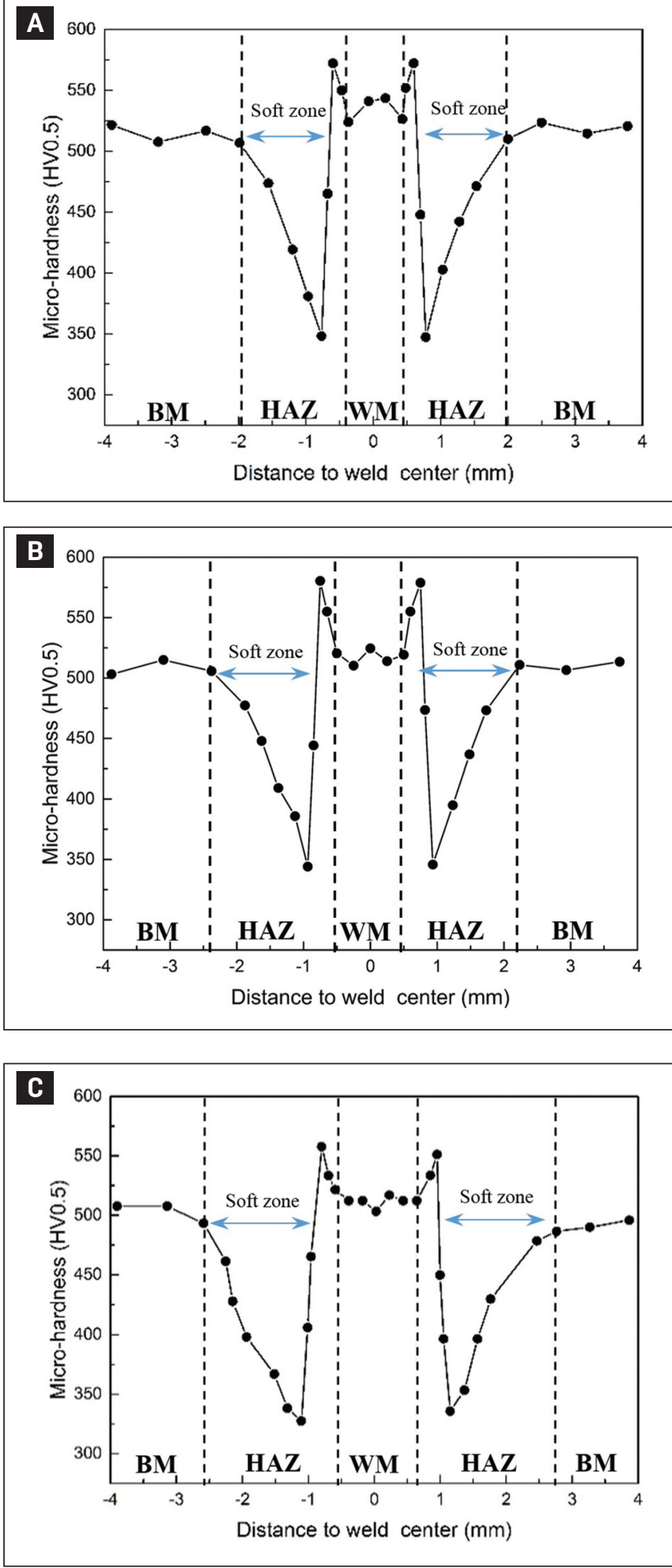

Fig. 12 - The hardness distribution of the joint under different heat inputs. $A-0.16 \mathrm{~kJ} / \mathrm{mm}$; $B-0.18 \mathrm{~kJ} / \mathrm{mm}$; $C-0.30 \mathrm{~kJ} / \mathrm{mm}$.

creased gradually from the SCHAZ to the base metal and eventually reached the level of base metal. For arc welded UHSS with similar strength and thickness, the size of the soft zone in the HAZ is about 6 to $8 \mathrm{~mm}$ (Refs. 14, 16, 17). As given in Fig. 12, the width of the soft zone is just about
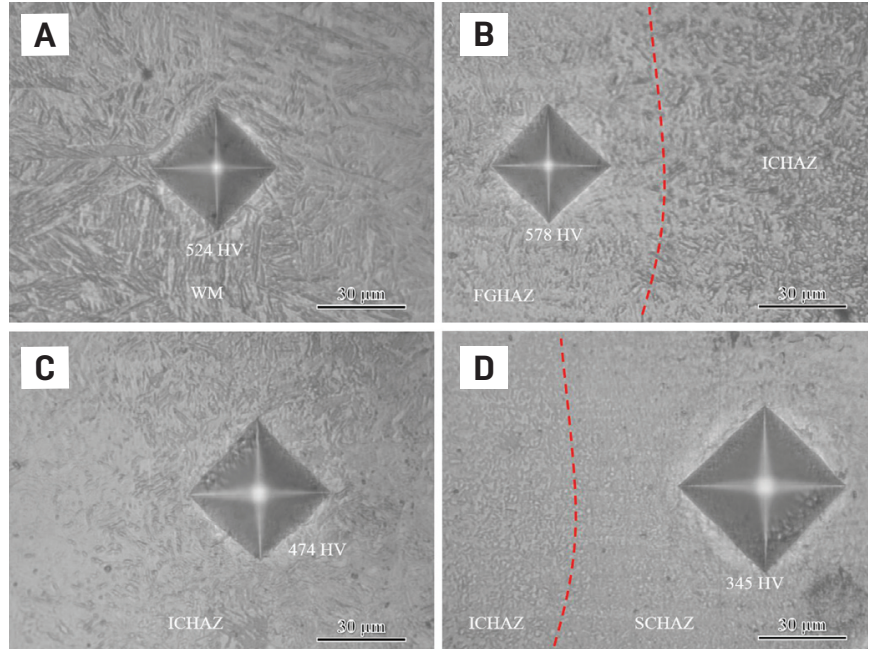

Fig. 13 - The microindentations of different subregions of the joint with $0.18 \mathrm{~kJ} / \mathrm{mm}$ heat input. $A-$ The WM around the weld center; B - FGHAZ; C - ICHAZ; D - SCHAZ

1.0 to $2.0 \mathrm{~mm}$, much less than the width of the arc-welded joint (Ref. 16). The limited size could reduce the influence of softening on the strength of the joint, but might lead to inhomogeneous deformation during a bend test.

As is expected, various heat cycles would lead to a different softening. As shown in Fig. 12, the width and minimum hardness of the softening zone are influenced by heat input. The width of the different joints were 1.31, 1.45, and 1.70 $\mathrm{mm}$, respectively. Additionally, the minimum hardness was 348,345 , and $327 \mathrm{HV}$, respectively. The high-heat-input weld exhibited a wider dimension and a more serious hardness drop in the softening zone compared to low heat input. The changes indicated that high heat input intensified the HAZ softening.

\section{Tensile Properties}

Tensile properties of the joints under different welding parameters are shown in Table 5 . It can be found that, while the elongation is lower for the laser welded joints, the ultimate tensile strength (UTS) remains very close to the base metal. In this study, the average strength of the joints was about $1620 \mathrm{MPa}$, which indicates that the joint efficiency can be more than $94 \%$, and far exceeds that of arc welding. The maximum elongation is $4.75 \%$, more than $50 \%$ of the base metal.

The tensile fracture sections of the joints under different heat input are given in Fig. 14. Because of light corrosion, only the ICHAZ can be seen clearly. As shown in the figure, the fracture location shifts from the weld metal to the HAZ with the increase of heat input. Two distinctive fracture modes are observed and the corresponding SEM micrographs of the fracture surface are given in Figs. 15 and 16.

For the joint with the $0.16 \mathrm{~kJ} / \mathrm{mm}$ heat input (parameter 1), the failure was located in the weld metal around the weld center - Fig. 14A. A number of pores can be seen clearly on the macroscopic fracture surface - Fig. 15. It is indicated that porosity in the joints might weaken the weld metal and finally lead to the fracture in the region instead of the softening zone. Area measurements revealed that the reduction 


\begin{tabular}{|c|c|c|c|c|c|c|c|}
\hline No. & $\begin{array}{l}\text { Laser Power } \\
\text { (kW) }\end{array}$ & $\begin{array}{l}\text { Speed } \\
(\mathrm{m} / \mathrm{min})\end{array}$ & $\begin{array}{l}\text { Heat Input } \\
(\mathrm{kJ} / \mathrm{mm})\end{array}$ & $\begin{array}{c}\text { Tensile Strength } \\
\sigma_{\text {UTS }}(\mathrm{MPa})\end{array}$ & $\begin{array}{c}\text { Elongation } \\
\mathrm{A}(\%)\end{array}$ & $\begin{array}{l}\text { Fraction } \\
\text { Location }\end{array}$ & $\begin{array}{l}\text { Initiation } \\
\text { Location }\end{array}$ \\
\hline 1 & 8 & 3 & 0.16 & 1618.0 & 3.15 & weld metal & weld metal \\
\hline 2 & 6 & 2 & 0.18 & 1623.5 & 4.75 & weld metal/HAZ & HAZ \\
\hline 3 & 10 & 2 & 0.30 & 1618.0 & 4.55 & weld metal/HAZ & HAZ \\
\hline BM & - & - & - & 1723.0 & 9.05 & - & - \\
\hline
\end{tabular}
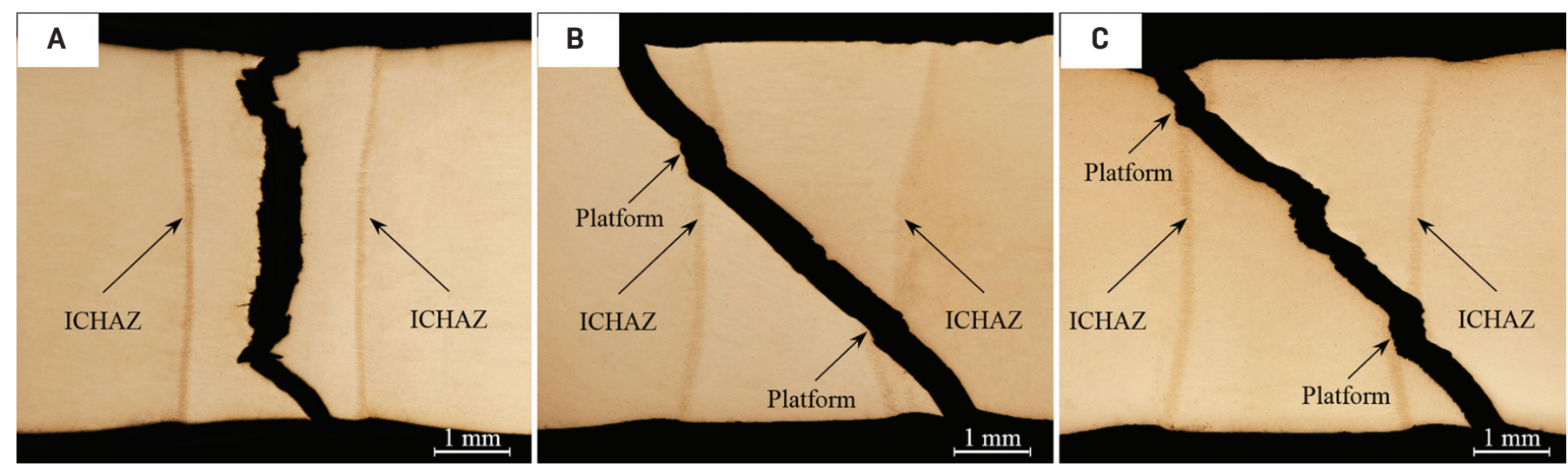

Fig. 14 - The fracture sections after tensile testing of the joints under different heat inputs. $A-0.16 \mathrm{~kJ} / \mathrm{mm} ; \mathrm{B}-0.18 \mathrm{~kJ} / \mathrm{mm}$; $\mathrm{C}-$ $0.30 \mathrm{~kJ} / \mathrm{mm}$.
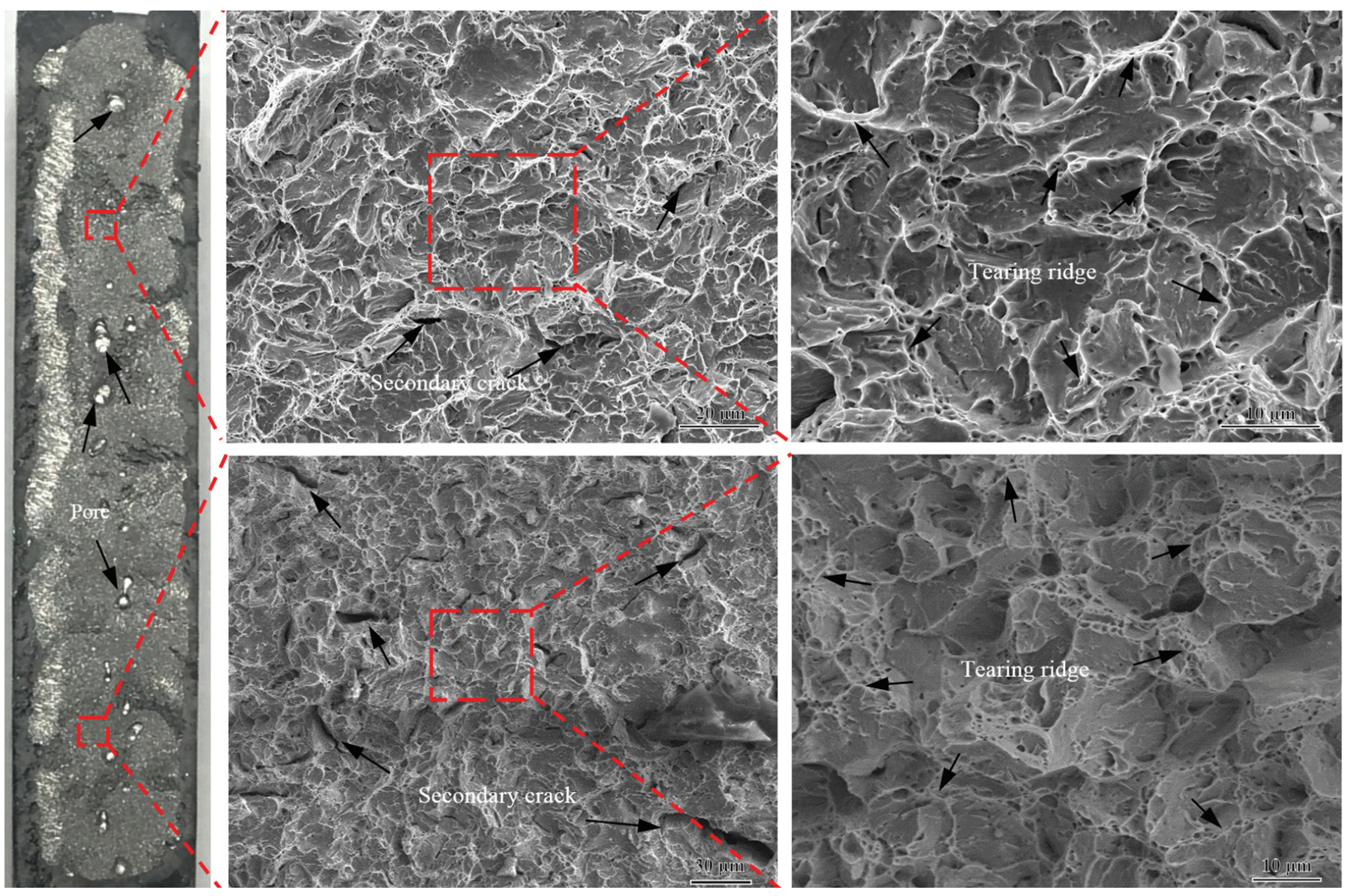

Fig. 15 - The SEM micrographs of the fracture surface after the tensile test of the joints welded at a heat input of $0.16 \mathrm{~kJ} / \mathrm{mm}$. 

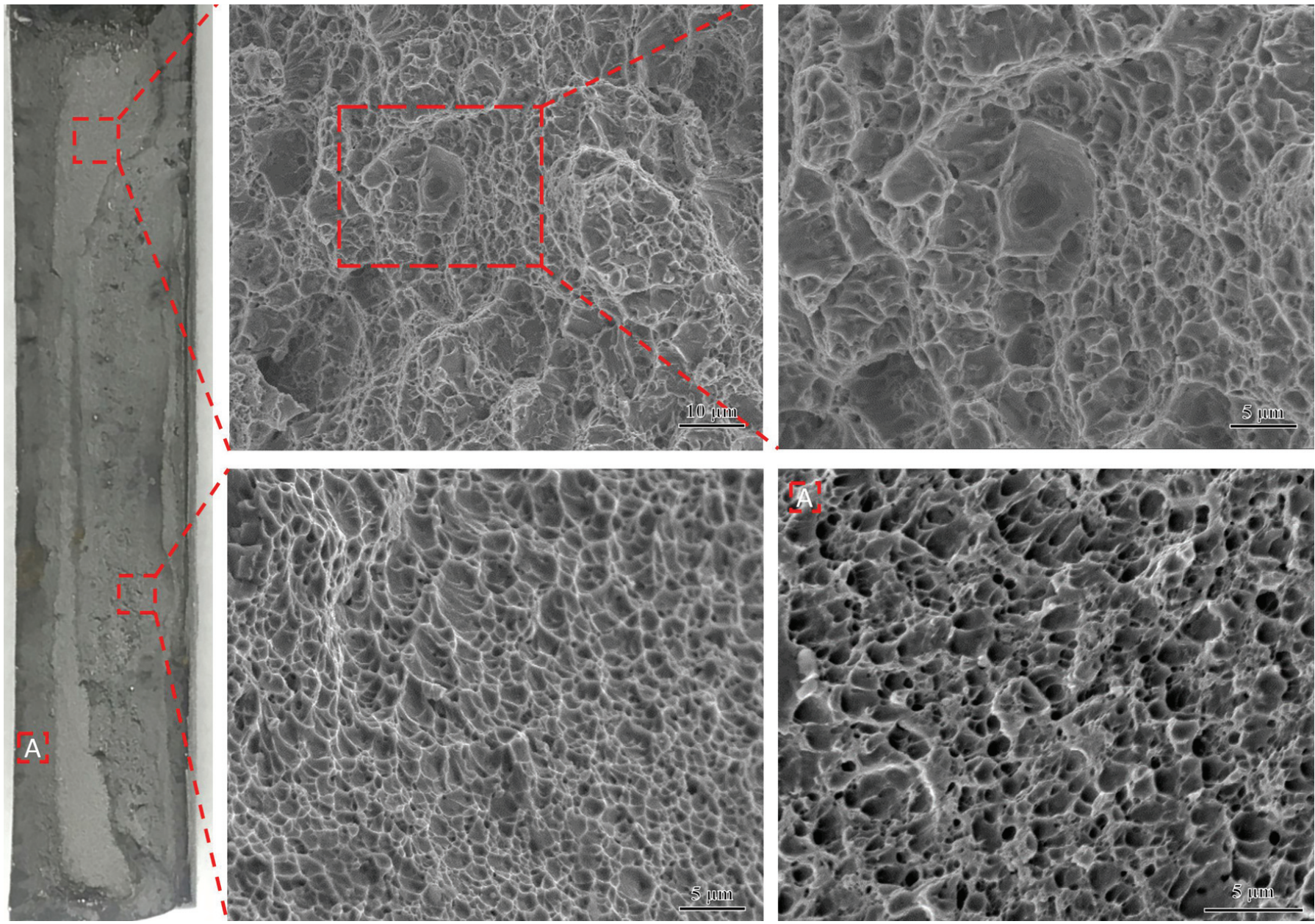

Fig. 16 - The SEM micrographs of the fracture surface after the tensile test of the joints welded at a heat input of $0.30 \mathrm{~kJ} / \mathrm{mm}$.

Table 6 - Bending Results of Laser Welded Joints

\begin{tabular}{lccccc} 
No. & $\begin{array}{c}\text { Laser Power } \\
(\mathrm{kW})\end{array}$ & $\begin{array}{c}\text { Speed } \\
(\mathrm{m} / \mathrm{min})\end{array}$ & $\begin{array}{c}\text { Heat Input } \\
(\mathrm{kJ} / \mathrm{mm})\end{array}$ & $\begin{array}{c}\text { Maximum Bending Angle } \\
(\mathrm{deg})\end{array}$ & $\begin{array}{c}\text { Bending Fraction } \\
\text { Location }\end{array}$ \\
\hline 1 & 8 & 3 & 0.16 & 21.4 & Weld metal \\
2 & 6 & 2 & 0.18 & 43.8 & $\mathrm{HAZ}$ \\
3 & 10 & 2 & 0.30 & 38.2 & $\mathrm{HAZ}$ \\
Base metal & - & - & - & 180.0 & - \\
\hline
\end{tabular}

ratio due to porosity is just about $0.65 \%$. As illustrated in Fig. 15, numerous short tearing ridges are observed on the fracture surface of the joints. Tiny cleavage planes connect with each other through the tearing ridge, accompanied by a secondary crack. All of the above is a typical feature of quasi-cleavage mode, which belongs to a brittle transgranular fracture. Moreover, some small dimples can be observed. The existence of dimples and tearing ridges means some plastic deformation occurred before the fracture. Thus, the fracture mechanism is a dominant brittle fracture, mixed with a measure of ductile fracture.

For the joints with more than $0.18 \mathrm{~kJ} / \mathrm{mm}$ heat input (parameters 2 and 3), the fracture was located in the HAZ and the weld metal (Fig. 14B and C). Platforms close and parallel to the ICHAZ can be seen. The microstructure in the platforms is severely tempered martensite with large amounts of precipitates carbides, and the hardness is the lowest. Therefore, the welded joints would break off at the softened area and then expand to other zones of the joints (Refs. 4, 39). The overall fracture direction is along 45 deg to the parallel direction. Various magnification SEM fracture graphs for the welded specimen are shown in Fig. 16. The fracture morphology in the platform is similar. It can be seen that the platform is predominately composed of different-sized equiaxed dimples, which are caused by simple tensile loading, and the morphology is usually in accordance with the characteristic of the fracture center (Refs. 40, 41). The graphs on the two 45-deg shear planes beside the plat- 

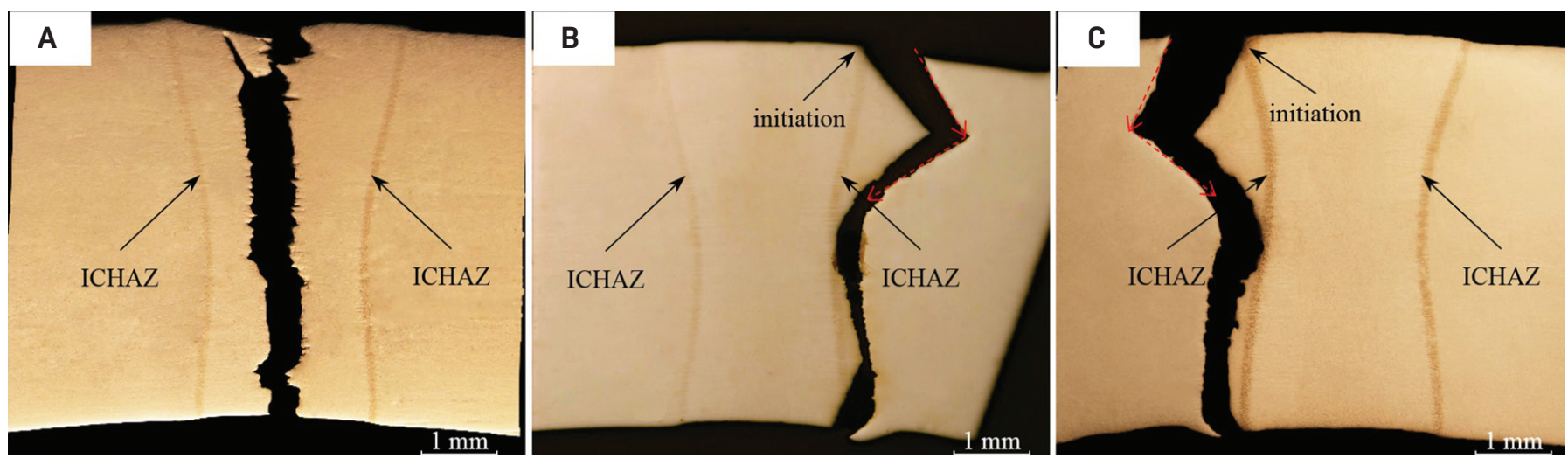

Fig. $17-$ The fracture sections of the bending joints under different heat input. A $-0.16 \mathrm{~kJ} / \mathrm{mm} ; B-0.18 \mathrm{~kJ} / \mathrm{mm} ; C-0.30 \mathrm{~kJ} / \mathrm{mm}$.

A

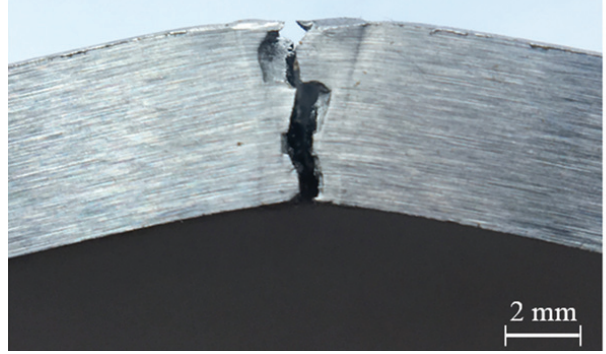

B

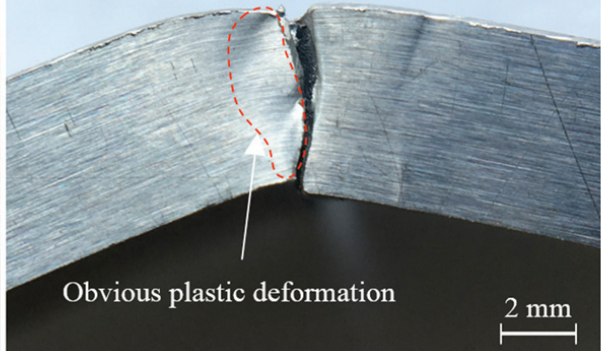

C

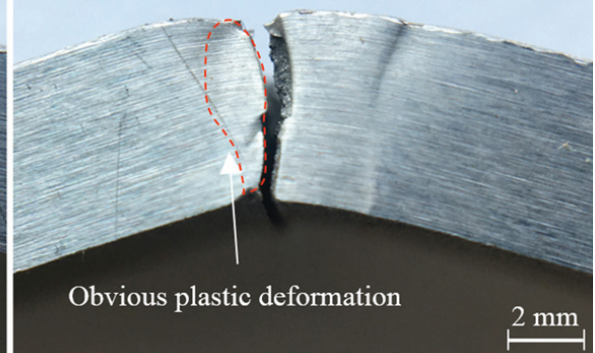

Fig. 18 - The macrographs of bending joints under different heat inputs, $A-0.13 \mathrm{~kJ} / \mathrm{mm} ; B-0.18 \mathrm{~kJ} / \mathrm{mm} ; C-0.30 \mathrm{~kJ} / \mathrm{mm}$.

form show small shearing dimples. The dimples have an elongated parabolic shape, indicating the occurrence of shearing motion and the final rapid failure of the sample (Refs. 42, 43). Combined with the minimum hardness on the platform, it is speculated that the fracture might initiate at the platform and then extend along the $45-$ deg bevel. It could be concluded that the specimen failed in a typical ductile fracture mode. That is why the elongation is larger compared with parameter 1 .

\section{Bending and Charpy Impact Properties}

A three-point bend test was carried out at the top of the joints to evaluate the bending property of joints. The results are shown in Table 6. Compared with the base metal, the laser welded joints have inadequate bending deformability with only about a 40-deg bending angle before a complete fracture was obtained. The base metal can easily realize a 180-deg bending angle without a crack.

The fracture sections and macrograph of bending joints under different heat input are given in Figs. 17 and 18, respectively. As shown in Fig. 17, two different fracture locations are observed.

For parameters with a $0.16 \mathrm{~kJ} / \mathrm{mm}$ heat input (parameter 1 ), the bending fracture occurred in the weld metal (Figs.

17A and 18A), where the metal is weakened by porosity, just like the tensile fracture. Since the plasticity of the weld metal is very poor with a hardness of more than $500 \mathrm{HV}$, only a 21.4-deg bending angle was obtained.

For parameters with a heat input of more than 0.18 $\mathrm{kJ} / \mathrm{mm}$ (parameters 2 and 3 ), the bending samples fractured around the softening zone instead of the weld metal. The larger bending angle (35.8 to $43.8 \mathrm{deg}$ ) is achieved because of better plasticity in the zone. A similar bending angle was reported in laser welded ARMOX 500T steel (Ref. 9). During a bend test, the specimen surface had the maximum tensile stress. Therefore, the fracture might initiate at the top of around the ICHAZ (Fig.17) where the hardness is the lowest. The fracture locates in the SCHAZ. The microstructure around the fracture zone is tempered martensite with different temper temperatures. The degree of the temper reduces progressively away from the weld center. Just like the tension process, it extended along a 45-deg shear plane in the initial stage. As the testing proceeded, the fracture turned around about $90 \mathrm{deg}$ and extended along the 45-deg direction again (extending stage) since the hardness of the SCHAZ increased gradually away from the weld center. Finally, the samples ruptured along the ICHAZ. The SEM micrographs of the fracture surface on the tension stress zone of bending samples are given in Fig. 19. On both the 45-deg bevels, cleavage surface can be seen clearly, which indicates that the fracture mechanism of the two bevels is a brittle fracture.

As shown in Figs. 17 and 18, no joints were subjected to significant plastic deformation and all the joints failed. This can be explained by the fact that, as illustrated in Fig. 18B 

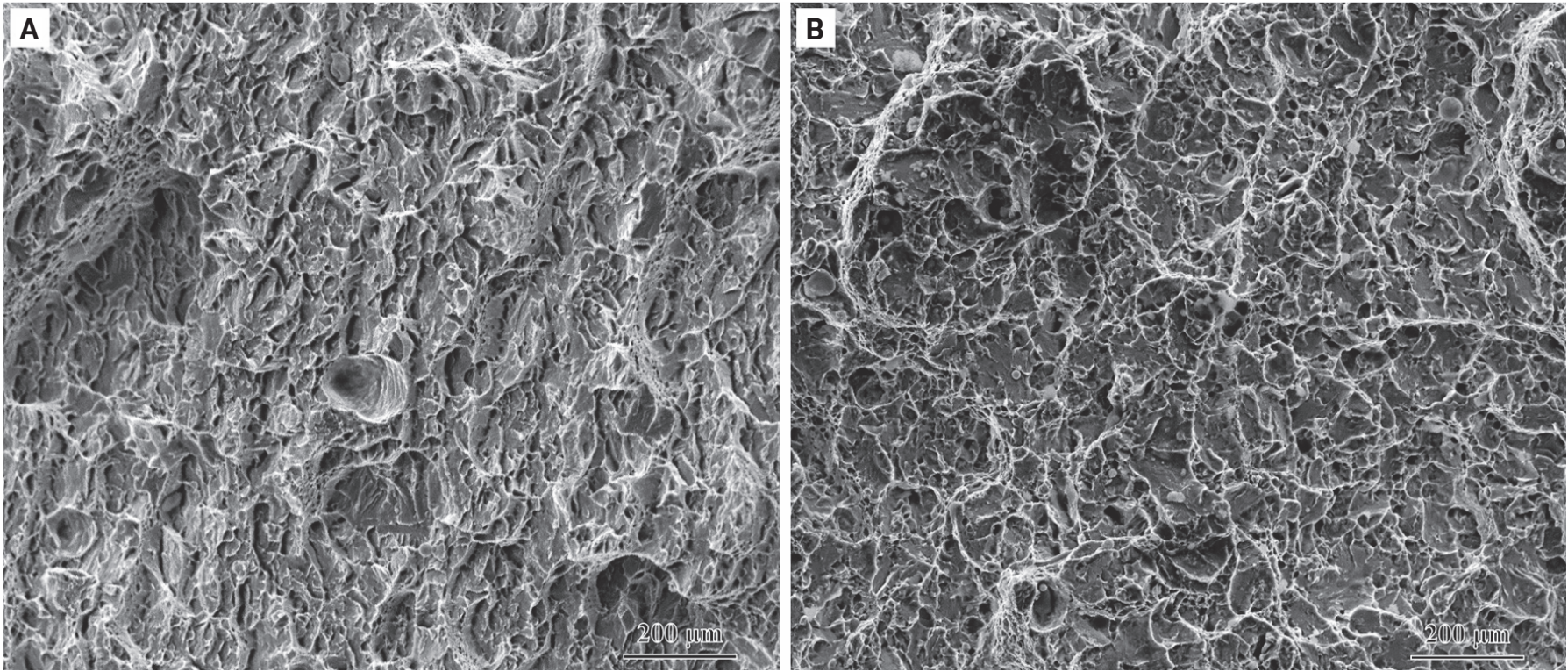

Fig. 19 - SEM micrographs of the fracture surface on the tension stress zone of the bending samples at the heat input of 0.18 $\mathrm{kJ} / \mathrm{mm}$. A - 45-deg shear plane in the initial stage; $B-45$-deg shear plane in the extending stage.

Table 7 - Impact Results of Laser Welded Joints

\begin{tabular}{lccccc} 
No. & $\begin{array}{c}\text { Laser Power } \\
(\mathrm{kW})\end{array}$ & $\begin{array}{c}\text { Speed } \\
(\mathrm{m} / \mathrm{min})\end{array}$ & $\begin{array}{c}\text { Heat Input } \\
(\mathrm{kJ} / \mathrm{mm})\end{array}$ & $\begin{array}{c}\text { Impact Energy } \\
\left(-40^{\circ} \mathrm{C}, \mathrm{J}\right)\end{array}$ & $\begin{array}{c}\text { Impact Fraction } \\
\text { Location }\end{array}$ \\
\hline 1 & 8 & & & 4.3 & Weld metal \\
2 & 6 & 3 & 0.16 & 8.7 & Weld metal \\
3 & 10 & 2 & 0.18 & 6.7 & Weld metal \\
Base metal & - & 2 & 0.30 & 14.3 & - \\
\hline
\end{tabular}

and $C$, plastic deformation mainly localizes in the softening zone due to nonuniform hardness distribution. Since the softening zone of a laser welded joint is narrow, allowable deformation is insufficient for a larger bending angle before fracture. Therefore, this may limit the deformability of all the joints.

The Charpy impact test of the base metal was carried out and the V-notch was located in the weld center of the joint. Impact results are shown in Table 7. The impact energies under different parameters are in the range of 4.3 to $8.7 \mathrm{~J}$, and the maximum impact energy is more than $60 \%$ of the base metal. The macroscopical fracture surfaces of the base metal and joints are shown in Fig. 20. The fibrous region is circled in the figures. It can be seen that the fracture surface of the base metal is mainly comprised of a fibrous region and shear lip. However, for the laser welded joints, the fracture surface is composed of a large range of a radia region and a small range of fibrous region without shear lip, which indicates that the fracture mechanism is mainly a brittle fracture. Hence, the impact energy of the joint is much less than that of the base metal. Since the V-notches located in the weld center and the entire fracture of joints is almost a plane, the cracking initiates and propagates around the weld center. This may result from obvious direction of columnar grains in the weld center (Fig. 8).

\section{Discussion}

\section{Influence of Parameters on Joint Appearance}

As shown in Fig. 3, parameters obviously affect the distribution of forming defects. Spatter mainly occurred in highspeed welds. It is reported that spatters are caused by the upward melt flow and friction drag force (Ref. 32). The melt flow is due to the evaporation-induced recoil pressure, and the drag force is induced by metallic vapor escaping from the keyhole (Refs. 32, 44). With an increase in welding speed, the length of the molten pool is longer and the inclination of the capillary becomes larger, which would result in stronger dynamic pressure of the vapor plume and more spatter (Ref. 45). In this research, smooth and uniform welds with few spatters can be obtained with a welding speed below $4 \mathrm{~m} / \mathrm{min}$.

Root humping is mainly affected by low heat input under high welding speed. Relevant studies have demonstrated that it is associated with the fast downward melt flow (Ref. 33). The molten metal flows rearward under the effect of recoil pressure and forms a droplet at the bottom due to inertia. Usually the droplets would be dragged back to the weld before solidification by surface tension, but small heat input (6 $\mathrm{kW}$ and $4 \mathrm{~m} / \mathrm{min}$ ), with high cooling rate, shortens the 

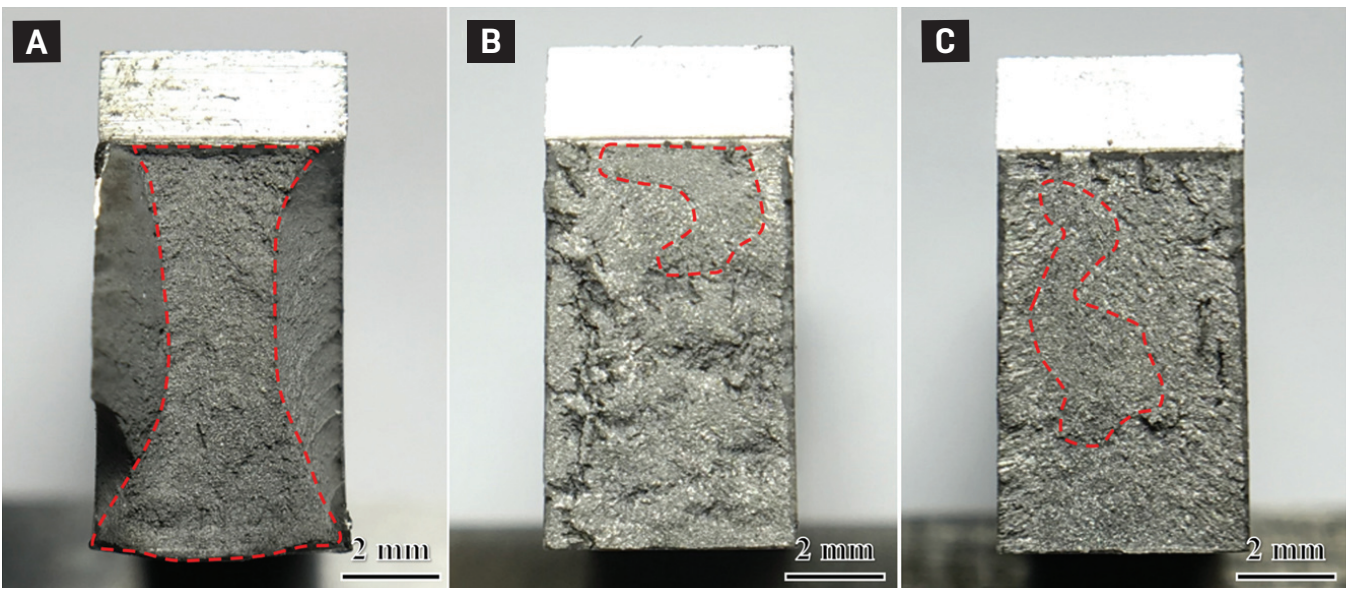

D

Fig. 20 - Impact fractures of the base metal and joints. A - The base metal; B $-0.16 \mathrm{~kJ} / \mathrm{mm} ; C-0.18 \mathrm{~kJ} / \mathrm{mm} ; D-0.30 \mathrm{~kJ} / \mathrm{mm}$.

time of solidification and the droplets are retained in the form of root humping instead of retuning into the weld. As a result, root humping occurs and leads to underfill on the corresponding cross section.

Weld pool sagging is one of the characteristics of a thick section weld (Ref. 10). Once the melt pool is fully penetrated, pool sagging occurs. It might be associated with an amount of molten metal produced by the excessive heat input and the downward melt flow with root humping. Gravity in the thick-section molten pool is as important as surface tension and recoil pressure. Once the plate is fully penetrated, the molten metal flows toward the root of the weld under the action of hydrostatic pressure from gravity and the laser beam (Ref. 33). The dimensionless Bond number represents the ratio of gravitational forces to surface tension forces (Ref. 46). With the increase of the Bond number, the relative importance of gravity is becoming obvious. When the Bond number exceeds threshold levels, namely the gravity is large enough and the surface tension cannot compensate the hydrostatic pressure, pool sagging occurs (Refs. 10, $30,33)$. Too low a welding speed with excessive heat input would aggravate the defect. Maybe that is why serious pool sagging happened at $1 \mathrm{~m} / \mathrm{min}$. With a further increase in heat input, surface tension is totally unable to balance the hydrostatic pressure, molten metal is partly out of the weld, and then a significant root concavity appears (Fig. 4D).

\section{Softening Mechanisms of the HAZ}

The results described in the microstructure and microhardness sections indicate that the lath martensite in the weld metal, CGHAZ, and FGHAZ resulted in hardening of the joints. But the ICHAZ and SCHAZ showed microstructure degradation and hardness decreased, which would have a significant impact on the mechanical behavior of the laser welded joints. The analysis indicated that there might exist two softening mechanisms in laser welded UHSS joints.

First, the joints are softened in the ICHAZ since the dualphase microstructure of the ferrite and martensite appeared. As shown in Fig. 10A, the ferrite appeared at $A_{c 3}$ and reached the maximum quantity at $A_{c 1}$. The corresponding volume of martensite deceased gradually as it approached the SCHAZ, which resulted in a sharp drop in the hardness of the ICHAZ. Second, the UHSS is also softened in the SCHAZ as the martensite in the original microstructure precipitates carbides and then forms tempered martensite (Fig. 11). Because the highest temper temperature is slightly lower than $A_{c 1}$, the most heavily tempered martensite appears in the SCHAZ close to the ICHAZ. Therefore, the most significant softening occurs in the zone. With the decrease of peak temper temperature from the SCHAZ to the base metal, the hardness rose gradually, but the SCHAZ still belonged to the softening zone. The results are consistent with previous research (Ref. 9).

\section{Fracture Mechanisms of Tensile and Bend Tests}

Since the tension stress zone of the bending process is similar to the tensile process, there exists homogeneity for the failure of the tensile and bending test. As shown in Figs. 14 and 17, the fractures might both initiate at the softening zone close to the ICHAZ, where the hardness is the lowest and the microstructure is tempered martensite under high temperature. Then the fractures extend along the 45-deg direction as the tangential stress is the maximal. As the tensile and bend tests have their respective characters, there are some differences for the initiation location and propagation path of the fracture. For the bend test, the top and root of the joints withstand tensile and compressive loadings, respectively. The stress on the specimen surface is the maximum, so it's very sensitive to softening. Therefore, the fracture initiates at the joint surface instead of inside. Moreover, the crack propagation paths of tensile and bending fractures are different. For the tensile test, since the softening zone is close to the ICHAZ and the ICHAZ is inclined because of the hourglass weld shape (Ref. 35), the fracture might have the inertia of extending along the incline into the weld metal quickly. It could be the reason why the crack propagated to the weld metal instead of trapping in the softening zone after initiation. For the bend test, the expanding process carried on slowly and gradually. The cracking path in the tension stress zone of the bend samples is all 45 deg in the SCHAZ, but there is a 90-deg turn, which may result from increasing hardness away from the weld center. A similar propagating path was reported and some simulations about the crack growth trajectory were done (Refs. 47, 48). 
Based on the maximum tangential stress (MTS) criterion (Ref. 47), the fracture path would deviate from the original crack line. The maximum tangential stress criterion or the minimum strain energy density criterion has been frequently used for predicting the angle of deflection (Ref. 47). For the 45-deg original crack, the deflecting angle is about 90 deg. In this research, the crack of the bending specimens extends along the 45-deg shear plane in the initial stage and then deviates from the crack tip. The deflecting direction is toward the loading point, namely tends to the weld.

\section{Influence of Porosity on Mechanical Properties}

The existence of porosity in joints has significant affects on the mechanical property of joints. For the tensile test, as mentioned above, there are some pores in the weld metal of joints with $0.16 \mathrm{~kJ} / \mathrm{mm}$ heat input (Fig. 6). However, the tensile strength of the joints can reach $1618 \mathrm{MPa}$, very close to average strength $(1620 \mathrm{MPa})$ under different parameters, which might mean that the appearance of porosity exhibits little effect on the strength of joints. For the tensile and bending fracture, the porosity weakened the weld metal and led to complete failing in the zone instead of initiating at the softening zone.

The smaller elongation (3.15\%) and bending angle (21.4 deg) are obtained for the joints with porosity. Namely, the fracture mechanism and ductility are significantly affected. The existence of pores might also damage the impact property of the joints with porosity. That is why the impact energy under parameter 1 is just about $4.3 \mathrm{~J}$ and significantly lower than other parameters. Related studies have shown mechanical properties are obviously affected by porosity (Ref. 49), but the sensitivity of the properties to porosity is different. Ductility and toughness are highly sensitive and the value would drop immediately as the porosity appears (Refs. 50, 51). This may be attributed to stress concentration and initial cracks at porosity (Ref. 52), but strength is tolerant of some porosity (Refs. 50, 51, 53, 54). For 5086H116 aluminum alloy welds, the tensile strength was not reduced until the porosity level increased above a 1\% vol-\% (Ref. 50). For Inconel ${ }^{\circledR} 690$ joints with equal to or less than $1.7 \%$ porosity area, the tensile strength is similar to that of the BM (Ref. 55). Namely, the tensile strength would not significantly reduce until the porosity exceeds a certain level (Refs. 50, 55). The reason may be that strength loss is proportional to loss in the cross-section area (Ref. 56). Therefore, the porosity in the laser welded UHSS joints has significant effects on ductility, toughness, and fracture mechanism but little on the strength of joints, since the area ratio of porosity is approximately $0.65 \%$.

\section{Conclusions}

Based on the results achieved in this study, the following conclusions are obtained.

1. Forming defects such as spatter, root humping, and pool sagging as well as root concavity occur under different parameters. The welding speed is the main affecting factor. Sound welds without visible defects are obtained under the process window of laser power from 6 to $10 \mathrm{~kW}$ and a welding speed from 2 to $3 \mathrm{~m} / \mathrm{min}$. Moreover, porosity is found in the joints with low-heat input $(0.16 \mathrm{~kJ} / \mathrm{mm})$.

2. The microstructures and hardness of joints keep a good corresponding relationship. In the weld metal and the CGHAZ, the microstructures are predominately lath martensite with high hardness. The maximum hardness locates in the FGHAZ, which is consistent with fine equiaxed martensite. Two softening mechanisms occur in the HAZ. A sharp hardness decrease occurs in the ICHAZ as it exhibits a dual-phase microstructure of ferrite and martensite. The minimum hardness of joints locates in the SCHAZ since the original microstructure precipitates carbides and forms tempered martensite.

3. More than $94 \%$ of the strength and $50 \%$ of the elongation of the base material are achieved in a tensile test. For the joints with more than $0.18 \mathrm{~kJ} / \mathrm{mm}$ heat input, the fracture initiates at the softening zone close to the ICHAZ and propagates to the weld metal and the SCHAZ along the 45-deg direction. The fracture is ductile with equiaxed and shearing dimples. For the bend test, as the deformation mainly localizes in the softening zone due to nonuniform hardness distribution, no joints are subjected to significant plastic deformation and all bend specimens fail. When heat input is more than $0.18 \mathrm{~kJ} / \mathrm{mm}$, the bending fracture initiates at the top of around the ICHAZ and extends along the 45-deg shear plane with about a 40-deg bending angle. For the Charpy impact test, all the joints fractured in the form of brittle mechanism. The maximum impact energy reaches $60 \%$ of the base metal.

4. The existence of porosity in joints with $0.16 \mathrm{~kJ} / \mathrm{mm}$ heat input has significant effects on the ductility, toughness, and fracture mechanism but little on the strength of joints. For tensile and bend tests, porosity weakens the weld metal and leads to fracturing in the WM instead of initiating at the softening zone. The optimal parameter in this experiment is parameter 2 (6 $\mathrm{kW}$ and $2 \mathrm{~m} / \mathrm{min}$ ) with the best strength (1623.5 MPa), ductility (4.75\%), bending angle (43.8 deg), and impact toughness (8.7 J).

\section{References}

1. Roncery, L. M., Weber, S., and Theisen, W. 2012. Welding of twinning-induced plasticity steels. Scripta Materialia 66(12): 997-1001. DOI: 10.1016/j.scriptamat.2011.11.041.

2. Saha, D. C., Westerbaan, D., and Nayak, S. S. 2014. Microstructure-properties correlation in fiber laser welding of dualphase and HSLA steels. Materials Science and Engineering: A 607: 445-453. DOI: 10.1016/j.msea.2014.04.034.

3. Fahlstrom, K., Persson, K. A., and Larsson, J. K. 2016. Evaluation of laser weldability of 1800 and $1900 \mathrm{MPa}$ boron steels. Journal of Laser Applications 28(2): 022426-1 to 022426-7. DOI: $10.2351 / 1.4944102$.

4. Gu, Z., Yu, S., and Han, L. 2012. Influence of welding speed on microstructures and properties of ultra-high strength steel sheets in laser welding. ISIJ International 52(3): 483-487. DOI: $10.2355 /$ isijinternational.52.483.

5. El-Batahgy, A. M., Miura, T., and Ueji, R. 2016. Investigation into feasibility of FSW process for welding $1600 \mathrm{MPa}$ quenched and tempered steel. Materials Science and Engineering: A 651: 904-913. DOI: 10.1016/j.msea.2015.11.054.

6. Pramanick, A. K., Das, H., and Reddy, G. M. 2016. Development and design of microstructure based coated electrode for ballistic performance of shielded metal arc welded armour steel joints. Materials \& Design 103: 52-62. DOI: 10.1016/j.matdes.2016.04.058. 
7. Peterson, M. H., Brown, B. F., and Newbegin, R. L. 1967. Stress corrosion cracking of high strength steels and titanium alloys in chloride solutions at ambient temperature. Corrsion 23: 142-148. DOI: 10.5006/0010-9312-23.5.142.

8. Sandoz, G. 1972. A unified theory for some effects of hydrogen source, alloying elements, and potential on crack growth in martensitic AISI 4340 steel. Metallurgical Transactions 3(5): 1169-1176. DOI: 10.1007/BF02642449.

9. Janicki, D. 2014. Disk laser welding of armor steel. Archives of Metallurgy and Materials 59(4): 1641-1646. DOI: 10.2478/ amm-2014-0279.

10. Guo, W., Li, L., and Crowther, D. 2016. Laser welding of high strength steels (S960 and S700) with medium thickness. Journal of Laser Applications 28: 0224252-1 to 0224252-10. DOI: 10.2351/1.4944100.

11. Hamelin, C. J., Muransky, O., and Smith, M. C. 2014. Validation of a numerical model used to predict phase distribution and residual stress in ferritic steel weldments. Acta Materialia 75: 1-19. DOI: 10.1016/j.actamat.2014.04.045.

12. Yagodzinskyy, Y., Todoshchenko, O., and Papula, S. 2011. Hydrogen solubility and diffusion in austenitic stainless steels studied with thermal desorption spectroscopy. Steel Research International 82(1): 20-25. DOI: 10.1002/srin.201000227.

13. Magudeeswaran, G., Balasubramanian, V., and Reddy, G. M. 2008. Effect of welding processes and consumables on tensile and impact properties of high strength quenched and tempered steel joints. Journal of Iron and Steel Research International 15(6): 87-94. DOI: 10.1016/S1006-706X(08)60273-3.

14. Suresh, M. R., Sinha, P. P., and Sarma, D. S. 2007. Study of welding characteristics of $0.3 \mathrm{C}-\mathrm{Cr}$ Mo V (ESR) ultrahigh strength steel. Journal of Materials Science 42(14): 5602-5612. DOI: 10.1007/s10853-006-1115-3.

15. Pek, N. E., and Elaldi, F. 2012. Analysis of welding groove angle and geometry on strength of armor steel. Materials and Manufacturing Processes 27: 1437-1441. DOI: 10.1080/10426914.2012.709343.

16. Hanhold, B., and Babu, S. S. 2012. Investigation of HAZ softening in laser welding of AHS/high hardness steels. International Conference on Trends in Welding Research, pp. 19-25. Chicago, Ill. ASM International.

17. Murthy, N. K., Ram, G., and Murty, B. S. 2014. Carbide-free bainitic weld metal: A new concept in welding of armor steels. Metallurgical \& Materials Transactions B 45(6): 2327-2337. DOI: 10.1007/s11663-014-0120-1.

18. Magudeeswaran, G., Balasubramanian, V., and Balasubramanian, T. S. 2013. Effect of welding consumables on tensile and impact properties of shielded metal arc welded high strength, quenched and tempered steel joints. Science \& Technology of Welding \& Joining 13(2): 97-105. DOI: 10.1179/174329307X249432.

19. Magudeeswaran, G., Balasubramanian, V., and Reddy, G. M. 2014. Effect of welding processes and consumables on fatigue crack growth behaviour of armour grade quenched and tempered steel joints. Defence Technology 10(1): 47-59.

DOI: 10.1016/j.dt.2014.01.005.

20. Nemeček, S., Muzík, T., and Mísek, M. 2012. Differences between laser and arc welding of HSS steels. Physics Procedia 39: 67-74. DOI: 10.1016/j.phpro.2012.10.015.

21. Oyyaravelu, R., Kuppan, P., and Arivazhagan, N. 2016. Metallurgical and mechanical properties of laser welded high strength low alloy steel. Journal of Advanced Research 7(3): 463-472. DOI: 10.1016/j.jare.2016.03.005.

22. Roepke, C., and Liu, S. 2009. Hybrid laser arc welding of HY-80 steel. Welding Journal 88(8): 159-s to 167-s. DOI: 10.1017/CBO9781107415324.004.

23. Elmesalamy, A., Francis, J. A., and Li, L. 2014. A comparison of residual stresses in multi pass narrow gap laser welds and gas-tungsten arc welds in AISI 316L stainless steel. International Journal of Pressure Vessels and Piping 113: 49-59. DOI: 10.1016/j.ijpvp.2013.11.002

24. Sun, J., Liu, X., and Tong, Y. 2014. A comparative study on welding temperature fields, residual stress distributions and deformations induced by laser beam welding and $\mathrm{CO}_{2}$ gas arc welding. Materials \& Design 63(2): 519-530. DOI: 10.1016/j.matdes.2014.06.057.

25. Guo, W., Francis, J. A., and Li, L. 2016. Residual stress distributions in laser and gas-metal-arc welded high-strength steel plates. Materials Science and Technology 32(14): 1449-1461. DOI: 10.1080/02670836.2016.1175687.

26. Farrokhi, F., Siltanen, J., and Salminen, A. 2015. Fiber laser welding of direct-quenched ultrahigh strength steels: Evaluation of hardness, tensile strength, and toughness properties at subzero temperatures. Journal of Manufacturing Science and EngineeringTransactions of the ASME 137: 0610126-1 to 0610126-10. DOI: 10.1115/1.4030177.

27. Zhang, L., Lu, J. Z., and Luo, K. Y. 2013. Residual stress, micro-hardness and tensile properties of ANSI 304 stainless steel thick sheet by fiber laser welding. Materials Science and Engineering: A 561(3): 136-144. DOI: 10.1016/j.msea.2012.11.001.

28. Fahlstrom, K., and Larsson, J. 2013. Laser welding of 1900 MPa boron steels. The $14^{\text {th }}$ Nordic Laser Materials Processing Conference. Lulea University of Technology, Gothenbrug, Sweden.

29. Guo, W., Liu, Q., and Francis, J. A. 2015. Comparison of laser welds in thick section S700 high-strength steel manufactured in flat ( $1 G)$ and horizontal (2G) positions. CIRP Annals-Manufacturing Technology 64(1): 197-200. DOI: 10.1016/j.cirp.2015.04. 070.

30. Bachmann, M., Avilov, V., and Gumenyuk, A. 2014. Experimental and numerical investigation of and electromagnetic weld pool support system for high power laser beam welding of austenitic stainless steel. Journal of Materials Processing Technology 214(3): 578-591. DOI: 10.1016/j.jmatprotec.2013.11.013.

31. Li, S., Chen, G., and Katayama, S. 2014. Relationship between spatter formation and dynamic molten pool during highpower deep-penetration laser welding. Applied Surface Science 303: 481-488. DOI: 10.1016/j.apsusc.2014.03.030.

32. Zhang, M. J., Chen, G. Y., and Zhou, Y. 2013. Observation of spatter formation mechanisms in high-power fiber laser welding of thick plate. Applied Surface Science 280: 868-875. DOI: 10.1016/j.apsusc.2013.05.081.

33. Ilar, T., Eriksson, I., and Powell, J. 2012. Root humping in laser welding - An investigation based on high speed imaging. Physics Procedia 39: 27-32. DOI: 10.1016/j.phpro.2012.10.010.

34. Fang, X., Liu, H., and Zhang, J. 2015. Reducing the underfil rate of pulsed laser welding of titanium alloy through the application of a transversal pre-extrusion load. Journal of Materials Processing Technology 220: 124-134. DOI: 10.1016/j.jmatprotec. 2015.01.015.

35. Guo, W., Crowther, D., and Francis, J. A. 2015. Microstructure and mechanical properties of laser welded $S 960$ high strength steel. Materials \& Design 85: 534-548. DOI: 10.1016/j.matdes.2015.07.037.

36. Wang, B., Duan, Q. Q., and Yao, G. 2015. Fatigue fracture behaviour of spot welded B1500HS steel under tensile-shear load. Fatigue \& Fracture of Engineering Materials \& Structures 38(8): 914-922. DOI: 10.1111/ffe.12289.

37. Tamizi, M., Pouranvari, M., and Movahedi, M. 2016. Welding metallurgy of martensitic advanced high strength steels during resistance spot welding. Science \& Technology of Welding \& Joining 22(4): 1-9. DOI: 10.1080/13621718.2016.1240979.

38. Jia, Q., Guo, W., and Li, W. 2017. Experimental and numerical study on local mechanical properties and failure analysis of laser welded DP980 steels. Materials Science and Engineering: A 680: 378-387. DOI: 10.1016/j.msea.2016.10.121.

39. Hazratinezhad, M., Arab, N. B. M., and Sufizadeh, A. R. 2012. Mechanical and metallurgical properties of pulsed neodymium-doped yttrium aluminum garnet laser welding of dual phase 
steels. Materials \& Design 33(1): 83-87. DOI: 10.1016/ j.matdes.2011.06.070.

40. Sun, Z., and Yang, H. 2009. Microstructure and mechanical properties of TA15 titanium alloy under multi-step local loading forming. Materials Science and Engineering: A 523(1-2): 184-192. DOI: 10.1016/j.msea.2009.05.058.

41. Farabi, N., Chen, D. L., and Zhou, Y. 2012. Tensile properties and work hardening behavior of laser-welded dual-phase steel joints. Journal of Materials Engineering \& Performance 21(2): 222-230. DOI: 10.1007/s11665-011-9865-8.

42. Farabi, N., Chen, D. L., and Li, J. 2010. Microstructure and mechanical properties of laser welded DP600 steel joints. Materials Science and Engineering: A 527(4-5): 1215-1222. DOI: 10.1016/j.msea.2009.09.051.

43. Farabi, N., Chen, D. L., and Zhou, Y. 2011. Microstructure and mechanical properties of laser welded dissimilar DP600/ DP980 dual-phase steel joints. Journal of Alloys \& Compounds 509(3): 982-989. DOI: 10.1016/j.jallcom.2010.08.158.

44. Khairallah, S. A., Anderson A. T., and Rubenchik, A. 2016. Laser powder-bed fusion additive manufacturing: Physics of complex melt flow and formation mechanisms of pores, spatter, and denudation zones. Acta Materialia 108: 36-45. DOI: 10.1016/ j.actamat.2016.02.014.

45. Weberpals, J., and Dausinger, F. 2008. Fundamental understanding of spatter behavior at laser welding of steel. Proceedings of $27^{\text {th }}$ ICALEO, pp. 364-373. Temulca, Calif. Laser Institute of America.

46. Mahajan, M. P., Tsige, M., and Taylor, P. L. 1998. Paramagnetic liquid bridge in a gravity-compensating magnetic field. Physics of Fluids 10(9): 2208-2211. DOI: 10.1063/1.869742.

47. Ayatollahi, M.R., Aliha, M. R. M., and Hassani, M. M. 2006. Mixed mode brittle fracture in PMMA-An experimental study using SCB specimens. Materials Science and Engineering: A 417(1-2): 348-356. DOI: 10.1016/j.msea.2005.11.002.

48. Ban, H., Lm, S., and Kim, Y. 2015. Mixed-mode fracture characterization of fine aggregate mixtures using semicircular bend fracture test and extended finite element modeling. Construction and Building Materials 101: 721-729. DOI: 10.1016/j.conbuildmat. 2015.10.083.

49. Pessoa, E. C. P., Bracarense, A. Q., and Zica, E. M. 2006. Porosity variation along multipass underwater wet welds and its influence on mechanical properties. Journal of Materials Processing Technology 179(1-3): 239-243. DOI: 10.1016/j.jmatprotec.2006. 03.071 .

50. Ashton, R. F., Wesley, R. P., and Dixon, C. R. 1975. The effect of porosity on 5086-H116 aluminum alloy welds. Welding Journal 54(3): 95-s to 98-s.

51. Cao, X., and Jahazi, M. 2009. Effect of welding speed on butt joint quality of Ti-6Al-4V alloy welded using a high-power Nd:YAG laser. Optics and Lasers in Engineering 47(11): 1231-1241. DOI: 10.1016/j.optlaseng.2009.05.010.

52. Jana, S., Mishra, R. S., and Baumann, J. B. 2010. Effect of friction stir processing on fatigue behavior of an investment cast Al-7Si-0.6 Mg alloy. Acta Materialia 58(3): 989-1003. DOI: 10.1016/j.actamat.2009.10.015.

53. Springer, H., Kostka, A., and Santos, J. F. D. 2011. Influence of intermetallic phases and Kirkendall-porosity on the mechanical properties of joints between steel and aluminium alloys. Materials Science and Engineering: A 528(13-14): 4630-4642. DOI: 10.1016/j.msea.2011.02.057.

54. Wu, S. C., Yu, X., and Zuo, R. Z. 2013. Porosity, element loss, and strength model on softening behavior of hybrid laser arc welded $\mathrm{Al}-\mathrm{Zn}-\mathrm{Mg}-\mathrm{Cu}$ alloy with synchrotron radiation analysis. Welding Journal 92(3): 64-s to 71-s.

55. Kuo, T. Y., and Jeng, S. L. 2005. Porosity reduction in NdYAG laser welding of stainless steel and Inconel alloy by using a pulsed wave. Journal of Physics D Applied Physics 38(5): 722-728. DOI: 10.1088/0022-3727/38/5/009.

56. Rudy, J. F., and Rupert, E. J. 1970. Effects of porosity on mechanical properties of aluminum welds. Welding Journal 49(7): 322-s to 336-s.

CHONG LUO, YUE ZHAO (zhao-yue@tsinghua.edu.cn, and JIGUO SHAN (shanjg@tsinghua.edu.cn) are with the Department of Mechanical Engineering, Tsinghua University, Beijing, China. ZHAO and SHAN are also with the Key Laboratory for Advanced Materials Processing Technology, Ministry of Education, Tsinghua University, Beijing, China. YANG CAO is with the School of Materials, Tsinghua University, Beijing, China. LIN ZHAO and CAO are with the Central Iron \& Steel Research Institute, Beijing, China. 